\title{
Kink as a Form of Leisure: Kinky Events and the People who Love Them
}

\author{
Craig Webster, Ball State University, USA
}

Stanislav Ivanov, Varna University of Management, Bulgaria

\section{Chapter Summary}

In recent years, there has been a popularization of non-mainstream sexual/cultural practices. The sensation of Fifty Shades of Grey has led to the general public becoming increasingly aware of the kink/BDSM lifestyle. The BDSM/kink/sado-masochist lifestyle has largely thrived under the radar of many in the general public and the subculture/lifestyle has organized and held events for decades. In this article, we discuss the various events of the kink/BDSM subculture/lifestyle and illustrate the importance of the non-play events for those in the lifestyle. The authors have fielded two ground-breaking global surveys that delve into the prevailing social institution of the kink/BDSM lifestyle, The Munch, an event in which no BDSM activities take place. The intention of this research is to show the methods that participants and organizers use in order to protect the identity of those attending non-play BDSM events that take place in the general public. The findings show that those participating in munches, a popular form of non-play events, tend to use their real names, although there is a large minority that do not. The analysis intends to give insight into those who operate below the radar of society and still have a vibrant social scene.

The major contribution of this work is to show that kink/BDSM events can and do take place in public venues, but that participants and organizers work in ways to limit the exposure of participants, as there is a significant social stigma attached to being a member of the lifestyle. In addition, this research is linked with the development of kink/BDSM from the deviant to the mainstream (Tamazos et al., 2017) and shows how those things that had been traditionally out of the mainstream can now be exploited for commercial purposes. The research will show that there is a segment of the population that is currently holding events regularly and that these events and this market may be commercially exploited. 


\section{Learning Objectives:}

At the end of this chapter readers should be able to:

1. Identify the meaning of kink and BDSM.

2. Identify the different major typologies of kinkster events and the venues in which they commonly take place.

3. Understand the types of concerns that many organizers of kinkster events would have to consider in organizing events.

4. Understand the role of events for those involved in the kink/BDSM community.

\section{The Issue, Opportunity or Trend}

There is an indication that non-mainstream sexual practitioners are becoming an expanding market (Tomazos et al., 2017). In much of the world, there has been a shift towards accepting non-conventional expressions of sexuality. For example, prior to 1989 only Denmark legally recognized same-sex marriages but now many developed countries sanction this (Pew, 2017). Apart from the acceptance of homosexuality, other forms of sexual expression are also becoming increasingly accepted or known, specifically the kink/BDSM lifestyle. While the Fifty Shades of Grey franchise has helped to popularize the lifestyle, it has not led the lifestyle to mainstream acceptance. While the subculture generally lives outside of the norm, it exists and has events and tourism that is specifically geared to the subculture's needs.

Kink/BDSM are expressions of sexuality that are as enigmatic and all-encompassing as a person could imagine and generally refer to sexual practices/expressions that are not mainstream (Stockwell et al., 2010). The generic term used by those in this lifestyle/community to describe themselves is "kinksters." But not all kinksters are the same. To begin, both "kink" and "BDSM" are umbrella terms to express forms of human sexual expression. Kink is the most expansive of the umbrella terms as it is a very broad term that is a reference to practices that are linked with sexuality but are not necessarily sexual (Webster \& Ivanov, 2019). Such practices may include tickling, spitting, foot fetishes, or anything else that would seem to be odd, and in some cases, not necessarily sexual in nature. For example, a person at a kink party could ask to have another person floss her/his teeth. While this may be seen as good hygiene, it is also a matter of creating a sense of intimacy between two people that may not be directly sexual in nature. While many practices may not necessarily be overtly sexual in nature, there is a sensual/sexual component, as the person being tickled with a balloon, for example, would likely want the person tickling her/him to share a sense of sexual attraction. BDSM is also an umbrella term that is derived from "Bondage and Discipline, Dominance and Submission, and 
Sadism and Masochism." This umbrella term involves all sorts of practices and fetishes and is often used as a synonym for kink.

Estimating the size of the population of practitioners would be difficult or impossible to do, since many who practice things that are considered "kink" may not consider it "kink" nor necessarily do it regularly. In addition, many people have "kinky" thoughts, but never express them. While sexual practices are one thing, some data suggest that "kinky" fantasies are common in the general population (Joyal, Cossette, \& Lapierre, 2015; Joyal \& Carpentier, 2017). For example, in a recent survey over half of the 1,000 Quebecers surveyed indicated that they had had "kinky" fantasies and about a third of the respondents had expressed "kinky" behaviours (Joyal and Carpentier, 2017). Durex surveyed populations in 41 countries, finding that 5\% of respondents had taken part in sadomasochistic sex and that $20 \%$ had used such things as blindfolds, bondage, or masks in their private sex lives (Durex, 2005). An Australian study established that about $1.8 \%$ of the surveyed Australians participated in practices that would be deemed kink by most (Richters et al, 2008). A US study reported that approximately $10 \%$ of the population engage in BDSM (Masters et al., 1995). The data suggest that there is a significant number of kink/BDSM practitioners in developed countries, whether they identify with the lifestyle or community or not

Psychology is the field of study in which most of the academic research on kink is found. The psychological literature generally is concerned with why people are involved with kink and what benefits they receive from it (see, for example, Ardill \& O'Sullivan, 2005; Bauer, 2008; Baumeister, 1997; Chaline, 2010; Connolly, 2006; Cross \& Matheson, 2006; Dymock, 2012; Holt, 2016; Moser, 1988; Moser \& Levitt, 1987; Nichols, 2006; Richters et al., 2008; Sandnabba et al., 1999; Weinberg, Williams, \& Moser, 1984; Yost \& Hunter, 2012). However, there is very little literature that has delved into the events of the kink community, and much of the literature is quite recent (Graham, Butler, McGraw, Cannes, \& Smith, 2016; Webster 2018; Webster \& Klaserner 2019; Webster \& Ivanov, 2019; Weiss 2006). Weiss (2006) wrote about BDSM events and how they worked to create a sense of community in San Francisco. Graham et al. (2016) mention a form of a BDSM event but never define it as an event nor investigate the importance of the event for the community. Webster (2018) illustrated the reported concerns of kink event managers. Webster and Klaserner (2019) explained the same for those participating in kink events. Webster and Ivanov (2019) delved into the motivations for people to attend kinkster events and motivations of the organizers of such events.

There are three major findings that emerge from the literature on kinksters. First, those who practice kink/BDSM seem to be well-adjusted psychologically (Lindemann, 2011; Richters et al., 2008; Wismeijer \& van Assen, 2013). This suggests that practitioners are not psychologically damaged and have not experienced 
trauma that impacts upon them in their sex lives but are actually healthy in terms of their psychology and sexuality. Second, kink/BDSM may simply be thought of as a form of leisure (Newmahr, 2010), meaning that it is not necessarily just sexual expression but also simply a leisure activity, such as collecting stamps or attending concerts. Third, kink is going mainstream, meaning that there is increasing potential to exploit the lifestyle/subculture commercially (Tomazos et al., 2017). Taken as a whole, kinksters seem to be generally psychologically healthy people, simply expressing a pastime, rather than displaying psychological imbalance, and their lifestyle is now mainstream enough that it may be ready for commercial exploitation.

Kink/BDSM is relevant to tourism because there are many events and practices that offer opportunities for businesses, since this subculture holds many events and has many ways of taking part in the tourism economy. With changing approaches toward sexuality and changes in the way that subcultures can communicate, we see a growth in the business of kink events and tourism. There is a growth but there is a very real concern about one of the major aspects of kink events, the creation of rules that protect participants in ways that are beyond what is needed in more mainstream events, because many participants fear the repercussions of being involved with the kink lifestyle. In this piece, we explain some of the different types of events and event-related tourism of the kink community and explain some of the important needs of kink events and the specific concerns that those who deal with the kink events should think about, such as protecting the identities of those attending events.

\section{The Innovation}

\section{Case Context}

The kink/BDSM community holds many different types of events in many different venues. The major dichotomy between event types are those that are "play" events and "non-play" events (Webster and Klaserner, 2019). The "play" events take place in venues in which it could be expected that kink/BDSM activities may take place between those parties who have negotiated a "scene." Scenes could include spankings or other forms of corporal punishment, medical play (often using hypodermic needles to make geometric designs in a person's skin), degradation, or really anything that could be imagined and may include sex acts. The "non-play" events are usually simply social meetups and may include drinks or a meal enjoyed together among participants and will likely involve no kink/BDSM activities openly practiced. There may be a gray area in which there may be a "non-play" event in which some subtle kink/BDSM activities may take place, such as one person leading another by a leash or some language that would imply one person is another's 
"master." Table 1 illustrates different types of events and their characteristics, as well as examples of types of events.

Table 1: Kinkster Events and Characteristics

\begin{tabular}{|l|l|l|}
\hline & \multicolumn{1}{|c|}{ Play } & \multicolumn{1}{|c|}{ Non-Play } \\
\hline Venues & Public dungeon, private home & Public restaurant or bar \\
\hline Participation & Open to public or by invitation & Open to public \\
\hline Dress Code & $\begin{array}{l}\text { Specific to theme of the event } \\
\text { (may require nudity for certain } \\
\text { participants) }\end{array}$ & $\begin{array}{l}\text { Street dress, as not to attract } \\
\text { attention }\end{array}$ \\
\hline Cost to participant & Possible cover charge & Cost of food/drink consumed \\
\hline Examples of types of events & $\begin{array}{l}\text { Generic "Play Parties," high } \\
\text { protocol events, spanking events, } \\
\text { shibari workshops, nude happy } \\
\text { hour, femdom events, CMNF } \\
\text { events, CFNM events, flogging } \\
\text { workshops... }\end{array}$ & \begin{tabular}{l} 
Munch, Slosh, Kinky Drinkies, \\
\hline
\end{tabular} \\
\hline
\end{tabular}

The venues of events are varied. The word used to describe a common venue in which kink/BDSM is practiced is a "dungeon." There are individuals in the lifestyle who have their own personal dungeons and outfit them with the hardware that is needed for proper kink/BDSM play. These things include but are not limited to a St. Andrew's Cross (a cross frequently used in bondage), various pieces of furniture designed for binding a person, and various implements for corporal punishment. Since individuals have different tastes and likes, the types of accoutrements in the dungeon will be different. Dungeons may be found in private homes or may be available for public use, similar to any other hospitality establishment, such as a pub or restaurant.

In terms of the events available, the types and themes of events are only limited by the imagination of those organizing and attending. There may be a play party in either a public dungeon or a private one that has a female domination (femdom) or a CMNF (clothed male nude female) theme. At a femdom party, participants would expect females to dominate submissive participants and this may include the corporal punishment of males or the use of males as footstools or ashtrays, for those males who attend. There are also a variety of workshops, including bondage workshops and other forms of training.

In terms of non-play events, the dominant and probably most central institution is the munch. The munch evolved out of the socializing at a hamburger meetup in California during the 1980s (Weiss, 2006). It 
probably was referred to as a "munch" as participants would meet up and eat hamburgers in a social atmosphere. The term came to mean a non-play meetup in which people could socialize and different language is sometimes used to describe it (Webster and Klaserner, 2019). For example, in the UK, some meetups are referred to as "kinky drinkies" or "liquid munches" and are centered upon drinks, rather than food. A similar meetup in the Midwest of the USA and Canada is the "slosh." Munches and similar events typically take place in public, in restaurants and bars. \Munches and similar events are open events that occur in public spaces, although behavior and dress is used in ways to ensure that the meetup does not attract attention to itself and does not stand out from the other patrons of the venue.

Apart from these typical meetups (play and non-play events), there are other types of businesses and opportunities that can come from the meetups and business demands of the kinksters. Because some kink/sexual acts may take place, a venue that agrees to host the event will generally have to understand what it is getting into and usually ensure that others do not attend, apart from those who intentionally come for a kink/BDSM event. For example, dommetrips.com specializes in vacations in which a dominatrix oversees activities. Typically, such domme trips take place in a hotel/resort that is reserved just for the purposes of public kink, so that during the days that the group has booked the venue, kink activities will take place in public. Kinkbnb.com offers B and B experiences with overnights in venues with dungeons. Probably the best known and most massive of the commercial kink tourism operations is the Other World Kingdom (www.owk.cz), a 3 hectare (7.4 acre) estate in the Czech Republic in which male customers may pay to stay under conditions of female domination.

While there are many different commercial opportunities for businesses to get involved in, it was decided that the best place to start in terms of understanding the market for kink/BDSM products is the munch because it is a common gateway to new people who are interested in the kink/BDSM lifestyle. While most individuals who are curious about kink/BDSM would probably feel uncomfortable either going to a private party in a home in which there are various play activities going on or going to a public dungeon, most would console themselves with the knowledge that they are attending an event in which no kink/BDSM play will take place and which is held in a "normal" bar or restaurant. What makes the munch and similar events especially interesting to study is that they are clearly kink/BDSM events, but they generally occur in a hidden way but in the open. As such, the concerns of the organizers and the participants are different than they would be for a similar meetup for another groups that would not likely be targets for public scorn.

The innovation of kinkster events is that they show that substantial and important social events can be held with free labour, zero overhead costs, and participation fees that are set by those attending. For the 
most part, the organizers of munches work for free and are motivated not by money but by other things. Because the events typically take place in for-profit spaces available to the public, overhead costs for the organizers are nil. Munch venues, typically pubs or restaurants, are places where those in attendance decide how what each will consume in the venue, meaning that participants essentially set the price for herself/himself. In addition, the fact that these events are so common and occurring internationally indicates that there is substantial opportunity to develop commercially viable events for the community and there is evidence that this has already happened.

\section{Stakeholders Involved}

The major stakeholders in munches and similar events are organizers, participants, and the venues and the managers of the venues in which the events take place. Table 2 summarizes the stakeholders and their motivations, risks, and responsibilities. Probably the least important of the stakeholders are the venues and their management because these stakeholders need not know the nature and logic of the meetups that come to their restaurants/bars. The organizer will choose the venues largely based upon the characteristics of the venue that fit the needs of the group. Given that groups will have options and will generally not be blacklisted from venues, the role of the venues and their management is minimal, although it is clear that munches and similar events cannot take place unless a public venue is available.

Table 2: Munches and Stakeholders

\begin{tabular}{|l|l|l|l|}
\hline & \multicolumn{1}{|c|}{ Organizers } & \multicolumn{1}{c|}{ Participants } & \multicolumn{1}{c|}{ Venues } \\
\hline Motivation & $\begin{array}{l}\text { Status, social outlet, } \\
\text { introduction to new } \\
\text { members }\end{array}$ & $\begin{array}{l}\text { Curiosity, social outlet, } \\
\text { information about the } \\
\text { lifestyle }\end{array}$ & Money \\
\hline Risks & $\begin{array}{l}\text { Reputation, involvement in } \\
\text { quarrels between } \\
\text { participants }\end{array}$ & $\begin{array}{l}\text { Identity and interests known } \\
\text { to others }\end{array}$ & $\begin{array}{l}\text { Venue known to host } \\
\text { kinkster events }\end{array}$ \\
\hline Responsibilities & $\begin{array}{l}\text { Organizing venue and time, } \\
\text { marketing the event, } \\
\text { policing behavior at event, } \\
\text { establishing dress code }\end{array}$ & $\begin{array}{l}\text { Arriving at event, abiding by } \\
\text { rules of the event (including } \\
\text { dress code) }\end{array}$ & $\begin{array}{l}\text { Providing food/drink, as } \\
\text { per other customers }\end{array}$ \\
\hline
\end{tabular}

The other major stakeholder is the participant, the sine qua non for events. Participants may have different types of motivations. Some participants may be curious about kink/BDSM and some may be quite experienced in the lifestyle/subculture. Those who are less experienced may want to learn about the lifestyle 
while those who are more experienced may be looking for a social outlet or "play" partners. A specific concern of the participants is that they may be recognized as being part of the kink/BDSM lifestyle by attending a non-play event. Because non-play events tend to happen in public venues where other groups, families, and individuals come to eat and drink, there is a certain risk, given that a publicly-known affiliation with kink/BDSM may hurt a person's reputation or finances. Since kink/BDSM still is generally not fully understood by the general public and it may be considered an unacceptable form of sexual deviance, those who are known to associate with the lifestyle may be taking a risk. Many participants take precautions to protect themselves.

The final major stakeholder is the event organizer. Organizers of munches and similar events are a rather intriguing collection of people. They are very different from venues and their management who want to generate cash from the meetups, in contrast, the organizers do not stand to make money but will have to deal with complaints, marketing, and other unpleasantness associated with organizing events. Thus, it is likely that the organizers are motivated by other benefits, such as status in the community and the ability to meet and introduce new members to the lifestyle.

\section{Approach Used and the Impact}

To learn about the roles of the different stakeholders, two international surveys were fielded in English. Permission was gained from the Institutional Review Board of Ball State University and from the management of the largest online fetish social media, FetLife. A survey of munch participants was fielded from January to April of 2016 and a survey of munch organizers was fielded from December of 2016 to March of 2017. Although both were online surveys using the Qualtrics platform, the respondents were recruited in a slightly different way. In terms of the munch organizers survey, FetLife events were scanned to find the probable organizers of various events. Once individuals were identified, an invitation to take the survey was sent. For the munch participants survey, the researcher joined various groups and asked permission to post the survey link to the groups. Data collection stopped shortly after 1,000 responses were received for the munch participant survey and 200 responses were received for the munch organizers survey. Summary reports of the research findings are available to all and analysis of the gathered data can be found in the author's research (Webster 2018; Webster \& Klaserner 2019; Webster and Ivanov, 2019).

From the data received, we see that the munch organizers are a very experienced bunch. Of the 221 respondents who had organized an event, almost 59\% had organized more than twenty events. A bare majority (about $52 \%$ of respondents) were from the USA; while Canada, the UK, and Germany each had at 
least ten respondents. The organizers are a very educated group, with over $6 \%$ holding a doctorate and almost $19 \%$ with a master's degree. A plurality (41\%) are married/in a civil union, about $54 \%$ are childless, and about half are male. The most common age category is those between 46-60 years of age. Most of the respondents were never asked to organize munches or similar events and merely took on the responsibility for themselves.

The data show that the major concerns that they have are the setup of the venue to allow for private conversations, the location of the venue, the size of the venue, and the operating hours of the venue. Their major concerns with the food are that the food/drinks are of good quality and affordable. The data from the organizers also indicate that there is an interesting relationship with the venues, as about half have informed the management about the nature of the meetups, although only a minority (about 25\%) have said that they were asked if the meetups were for kinksters. The critical issue that they face when organizing meetups is that the venue affords privacy for group conversations.

Organizers do face many problems. In an open-ended question aimed to learn about the types of problems they typically face, the most common response is that people attending the events break rules, engage in inappropriate behaviour, or act in aggressive ways. The most common ways that organizers deal with such issues is that they explain the concerns to the participant and ask the participant to leave the event. Most interestingly, while munches and other such events are generally thought to exist below the radar, most organizers reported seeing visible symbols of the lifestyle at munches. The leading visible symbol reported is the collar, a symbol of submission.

In terms of the participants in munches and similar events, while only 993 respondents indicated the country they were based in, the majority (57\%) were located in the USA, while $22 \%$ reported being based in Europe. Interestingly, about $65 \%$ of respondents said that they use only their real name at the events, while $12 \%$ only use a pseudonym. Some attending munches and similar events are more open about their involvement in the kink/BDSM lifestyle. About $14 \%$ of respondent claim to be "very open," while $34 \%$ claim to be "somewhat open," $31 \%$ claim to be "somewhat secretive," and $21 \%$ claim to be "very secretive." The data suggest a bifurcated group of participants, some of whom are very open and use their real names and some who use pseudonyms and are careful about the open knowledge of their affiliation with the kink/BDSM lifestyle.

What is most interesting is the importance of the munch as an institution. For both surveys, the same question was asked about rating the importance of the munch. Figure 2 below shows that there is substantial evidence that the munch is a very important institution for the lifestyle. What is especially noteworthy is that the munch organizers rate the institution as being more important for the community than it is for themselves 
personally. This suggests that while the munch is almost universally recognized as a critical institution for the kink/BDSM community, organizers volunteer their time and efforts to ensure the continuation of the institution.

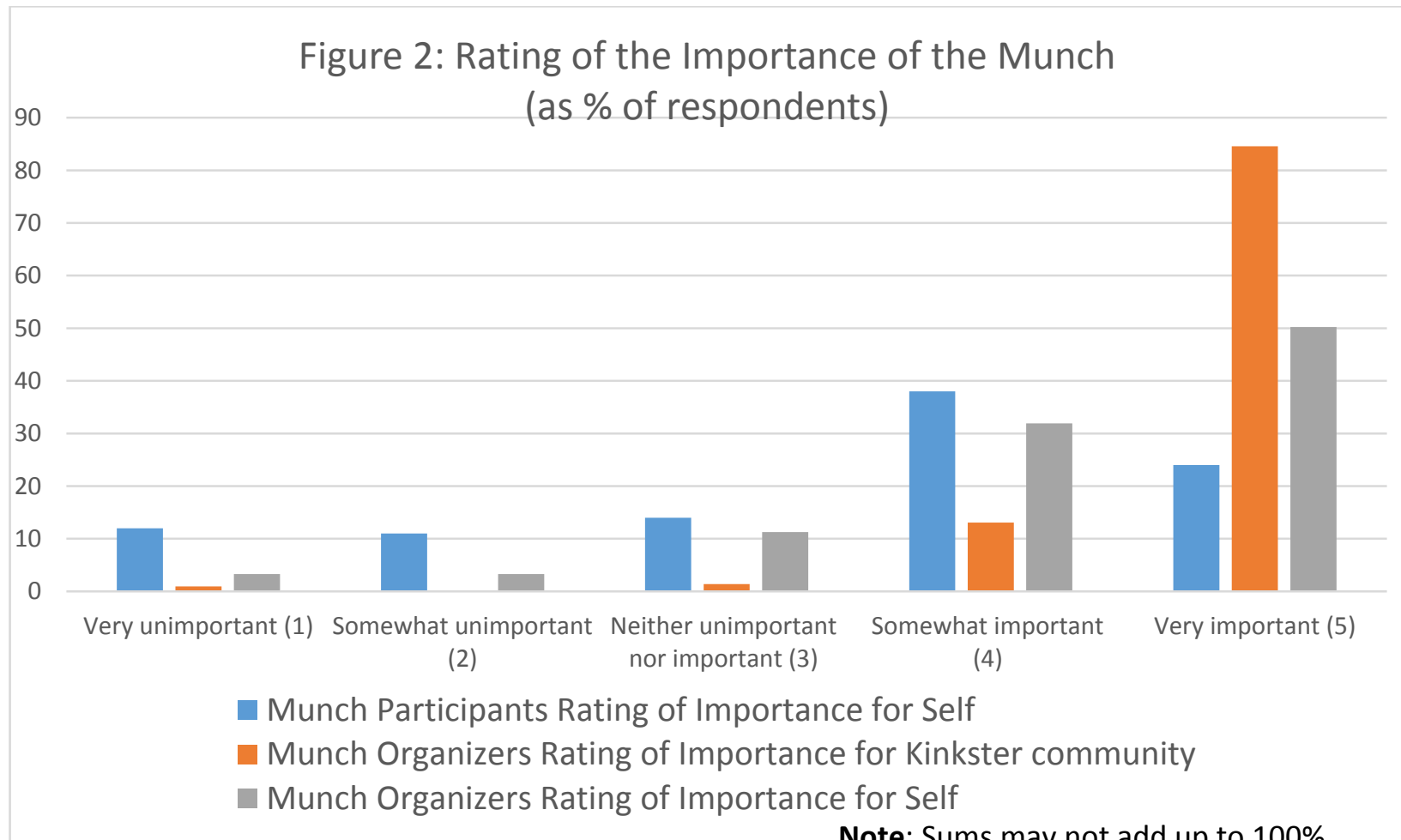

\section{Implications \& Lessons learned}

The findings illustrate a great deal about innovative leisure practices. First, a practice may not actually be particularly commercial nor visible to the general community to be important socially. The events discussed largely take place in public but under the radar of the general public and may be critical for a subculture and its practitioners.

What is also important is to look at the specific needs of the participants of munches. While many of the members of kink/BDSM community are "out" and are not concerned about whether their affiliation with the community is known, there is still a sizable contingent that is not out and is concerned about whether they are identified with or associated with the community. What this means for organizers is that they have to make the events consistent with the needs of those who fear repercussions from being associated with the lifestyle. Therefore, the organizers have to choose venues not only based upon cost, location, and quality of 
foods available but also based upon the need to protect the identity and conversations of the participants in events, something that those organizing more mainstream events would not have to worry about.

In addition, this study suggests that there is an expanding market for the provision of services for what has been a shunned sexual minority. While there may not be full acceptance of the practices of the kink/BDSM community in the general population, there seem to be commercial opportunities for many, and some may already be cashing in on kink/BDSM and not even realize it. For example, there may well be venues making money on the kink/BDSM culture without even knowing it, as they may unknowingly be hosting kink events.

Another finding of this research is the importance of the role of the self-selected volunteer to create and maintain events. While munches and similar events are not typically done for profit, a substantial number of people work very hard to make them happen, organizing for no financial reward. The anarchic methods of organization of kink/BDSM culture (although it may sound a bit like an oxymoron) may indicate something about how others can organize events on the cheap, using pre-existing commercial establishments and enabling participants to decide how much money and time they want to invest in the events.

This work also displays that there may be a substantial commercial opportunity, as kink/BDSM goes mainstream, as Tomazos et al. (2017) suggested. Society is changing and some elements are going mainstream. It seems logical that many of their market demands will become more obvious and may not have to be supplied in small batches and underground anymore. This could be a golden time to begin investing in tourism products for kinksters, as it seems that society is on the verge of acceptance of kinkster practices and communication technologies make information costs cheaper, enabling people to be informed about kink tourism products and have a society that accepts such practices. Now may be the time that economies of scale of products for kinksters can be developed.

\section{Discussion Questions}

1. If you were to organize a munch or "kinky drinkies" for some people in your town, how would you proceed to find a venue that would be appropriate for the meetup? Be specific about what aspects of the venue you would consider most important and what types of trade-offs there would be for your choices. Make sure you take into account that you want your event to be inclusive and well-attended. Maybe even discuss a specific venue in your town and discuss the benefits and drawbacks of the venue. 
2. How can people be kinksters and keep it a secret from many around them that they are part of the community? Be specific about how a kinkster would communicate with others and prevent it from being known that she/he is a kinkster while still enjoying the benefits of the lifestyle.

3. Imagine that you wanted to open a public dungeon in your town. What concerns would you have about the location and other aspects of it in order to make sure that participants in events there would be comfortable, safe, and have a good time? Your discussion should include concerns such as health and safety and the protection of the identities of those attending the events.

4. Why do people volunteer themselves to run munches in their towns? Discuss the motivations and how they may be similar or different to those of someone organizing meetings for less controversial interests, such as a meeting of stamp collectors or a book club.

\section{References}

Ardill, S., \& O'Sullivan, S. (2005). Upsetting an applecart: Difference, desire and lesbian sadomasochism. Feminist Review, 80(1), 98-126.

Bauer, R. (2008). Transgressive and transformative gendered sexual practices and white privileges: The case of the Dyke/Trans BDSM communities. Women's Studies Quarterly, 36(3-4), 233-253.

Baumeister, R. F. (1997). The enigmatic appeal of sexual masochism: Why people desire pain, bondage, and humiliation in sex. Journal of Social and Clinical Psychology, 16(2), 133-150.

Chaline, E. R. (2010). The construction, maintenance, and evolution of gay SM sexualities and sexual identities: A preliminary description of gay SM sexual identity practices. Sexualities, 13(3), 338-356.

Connolly, P. H. (2006). Psychological functioning of bondage/domination/sado-masochism (BDSM) practitioners. Journal of Psychology and Human Sexuality, 18(1), 79-120.

Cross, P. A., \& Matheson, K. (2006). Understanding sadomasochism: An empirical examination of four perspectives. Journal of Homosexuality, 50(2-3), 133-166.

Durex. (2005). 2005 Global Survey Results. http://www.data360.org/pdf/20070416064139.Global\%20Sex\%20Survey.pdf.

Dymock, A. (2012). But femsub is broken too! On the normalisation of BDSM and the problem of pleasure. Psychology and Sexuality, 3(1), 54-68. 
Graham, B. C., Butler, S. E., McGraw, R., Cannes, S. M., \& Smith, J. (2016). Member perspectives on the role of BDSM communities. Journal of Sex Research, 53(8), 895-909.

Holt, K. (2016). Blacklisted: Boundaries, violations, and retaliatory behavior in the BDSM community. Deviant Behavior, 37(8), 917-930.

Joyal, C. C., \& Carpentier, J. (2017). The prevalence of paraphilic interests and behaviors in the general population: a provincial survey. The Journal of Sex Research, 54(2), 161-171.

Joyal, C. C., Cossette, A., \& Lapierre, V. (2015). What exactly is an unusual sexual fantasy? Journal of Sexual Medicine, 12(2), 328-340.

Lindemann, D. (2011). BDSM as therapy? Sexualities, 14(2), 151-172.

Masters, W. H., Johnson, V. E., Kolodny, R. C., \& Bergen, M. B. (1995). Human sexuality. New York, NY: Harper Collins College Publishers.

Moser, C. (1988). Sadomasochism. Journal of Social Work and Human Sexuality, 7(1), 43-56.

Moser, C., \& Levitt, E. E. (1987). An exploratory-descriptive study of a sadomasochistically oriented sample. Journal of Sex Research, 23(3), 322-337.

Newmahr, S. (2010). Rethinking kink: Sadomasochism as serious leisure. Qualitative Sociology, 33(3), 313-331.

Nichols, M. (2006). Psychotherapeutic issues with kinky clients: Clinical problems, yours and theirs. Journal of Homosexuality, 50(2-3), 281-300.

Pew Research Center. (2017). Gay marriage around the world. http://www.pewforum.org/2017/08/08/gaymarriage-around-the-world-2013/

Richters, J., de Visser, R. O., Rissel, C. E., Grulich, A. E., \& Smith, A. M. (2008). Demographic and psychosocial features of participants in bondage and discipline, "sadomasochism" or dominance and submission (BDSM): Data from a national survey. The Journal of Sexual Medicine, 5(7), 1660-1668.

Sandnabba, N. K., Santtila, P., \& Nordling, N. (1999). Sexual behavior and social adaptation among sadomasochistically oriented males. The Journal of Sex Research, 36(3), 273-282. 
Stockwell, F. M. J., Walker, D. J., \& Eshleman, J. W. (2010). Measures of implicit and explicit attitudes toward mainstream and BDSM sexual terms using the IRAP and questionnaire with BDSM/Fetish and student participants. The Psychological Review, 60(2), 307-324.

Tomazos, K., O'Gorman, K. D., \& MacLaren, A. C. (2017) From leisure to tourism: How BDSM demonstrates the transition of deviant pursuits to mainstream products. Tourism Management, 60, 30-41.

Webster, C. (2018). Fifty shades of organizing kinkster events: Munch events in the BDSM community. International Journal of Hospitality and Event Management, 2(1), 19-37.

Webster, C. and Ivanov, S. (2019). Events are bound to happen: spank you very much. Event Management, (, 23(4-5), 669-684.

Webster, C. \& Klaserner, M. (2019). Fifty shades of socializing: slosh and munch events in the BDSM Community. Event Management, 23(1), 135-147

Weinberg, M. S., Williams, C. J., \& Moser, C. (1984). The social constituents of sadomasochism. Social Problems, 31(4), 379-389.

Weiss, M. D. (2006). Working at play: BDSM sexuality in the San Francisco Bay area. Anthropologica, 48(2), 229-245.

Wismeijer, A. A. J., \& van Assen, M. A. L. M. (2013). Psychological characteristics of BDSM practitioners. The Journal of Sexual Medicine, 10(8), 1943-1952.

Yost, M. R., \& Hunter, L. E. (2012). BDSM practitioners' understandings of their initial attraction to BDSM sexuality: Essentialist and constructionist narratives. Psychology and Sexuality, 3(3), 244-259. 


\section{Authors}

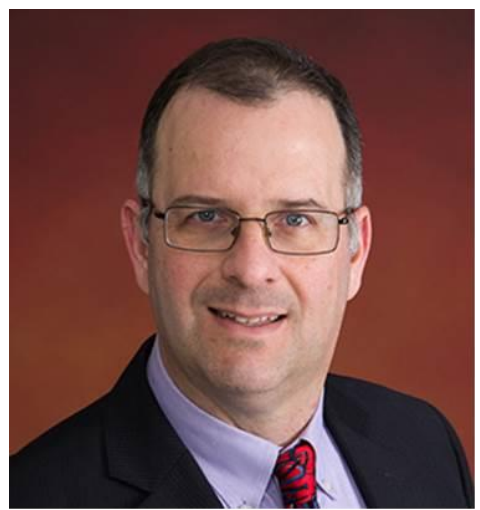

Craig Webster (Ph.D.) is an Associate Professor in the Department of Management at Ball State University, USA. He studied Government and German Literature at St. Lawrence University in New York State, received an MA and Ph.D. in Political Science from Binghamton University in New York State and an MBA Intercollege, Cyprus. He has taught at Binghamton University, Ithaca College, the College of Tourism and Hotel Management, and the University of Nicosia. His research interests include the political economy of tourism, public opinion analysis, and human rights. Dr. Webster is the Editor-in-Chief of Tourism Today, has published in many peer-reviewed journals internationally, and is co-editor of the book Future Tourism: Political, Social, and Economic Challenges, an edited book published by Routledge. His most recent book is Emerald Publishing's Robots, Artificial Intelligence and Service Automation in Travel, Tourism, and Hospitality, co-edited with Stanislav Ivanov. He currently teaches courses in Hospitality Management at Ball State University's Miller College of Business.

Email: cwebster3@bsu.edu

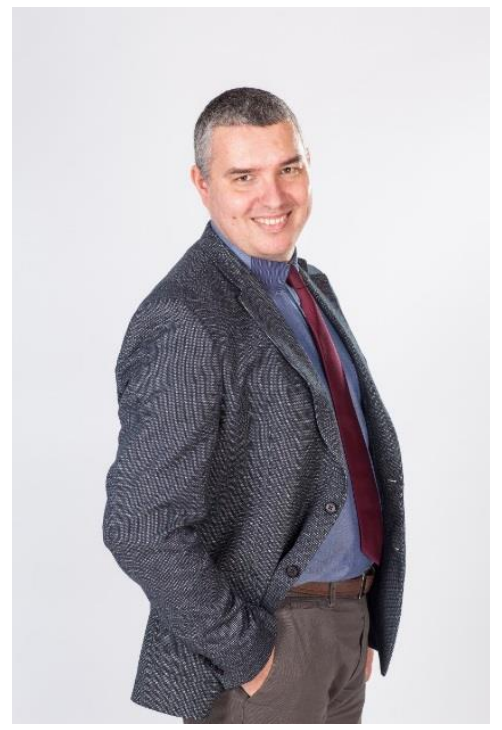

Stanislav Ivanov is currently Professor and Vice Rector (Research) at Varna University of Management, Bulgaria (http://www.vum.bg). Prof. Ivanov is the Founder and Editor-in-chief of the European Journal of Tourism Research (http://ejtr.vumk.eu) and serves in the Editorial boards of over 30 other journals. His research interests include robonomics, robots in tourism/hospitality, revenue management, destination marketing, tourism and economic growth, political issues in tourism, etc. His publications have appeared in different academic journals - Annals of Tourism Research, Tourism Management, Tourism Management Perspectives, International Journal of Revenue Management, Tourism Economics, Journal of Destination Marketing \& Management, Journal of Heritage Tourism,

Tourism Today, Tourism, Tourism and Hospitality Research, Tourism Planning and Development, International Journal of Hospitality and Tourism Administration, Technology in Society, Journal of Economic Studies, Journal of Southern Europe and the Balkans, South-Eastern Europe Journal of Economics and other journals. For more information about Prof. Ivanov please visit his personal website: http://www.stanislavivanov.com

Email: stanislav.ivanov@vumk.eu 